\title{
Phase I study of sorafenib combined with radiation therapy and temozolomide as first-line treatment of high-grade glioma
}

\begin{abstract}
A F Hottinger ${ }^{\star}, 1,2$, A B Aissa ${ }^{1}$, V Espeli ${ }^{1}$, D Squiban ${ }^{1}$, N Dunkel $^{1}$, M I Vargas ${ }^{3}$, T Hundsberger $^{4}$, N Mach $^{1}$, K Schaller ${ }^{5}$, D C Weber ${ }^{1,6}$, A Bodmer ${ }^{1}$ and P-Y Dietrich ${ }^{1}$

${ }^{1}$ Clinical Research Unit of the Foundation Dr Henri Dubois Ferriére Dinu Lipatti \& Centre of Oncology, Geneva University Hospitals and University of Geneva, Geneva, Switzerland; ${ }^{2}$ Department of Clinical Neurosciences \& Oncology, CHUV University Hospital and University of Lausanne, Lausanne, Switzerland; ${ }^{3}$ Department of Neuroradiology, Geneva University Hospitals and University of Geneva, Geneva, Switzerland; ${ }^{4}$ Department of Neurology and hematology/oncology, Cantonal Hospital St Gallen, St Gallen, Switzerland; ${ }^{5}$ Department of Neurosurgery Geneva University Hospitals and University of Geneva, Geneva, Switzerland and ${ }^{6}$ Department of Radio-oncology, Geneva University Hospitals and University of Geneva, Geneva, Switzerland
\end{abstract}

Background: Sorafenib $(\mathrm{Sb})$ is a multiple kinase inhibitor targeting both tumour cell proliferation and angiogenesis that may further act as a potent radiosensitizer by arresting cells in the most radiosensitive cell cycle phase. This phase I open-label, noncontrolled dose escalation study was performed to determine the safety and maximum tolerated dose (MTD) of Sb in combination with radiation therapy (RT) and temozolomide (TMZ) in 17 patients with newly diagnosed high-grade glioma.

Methods: Patients were treated with RT (60 Gy in 2 Gy fractions) combined with TMZ $75 \mathrm{mg} \mathrm{m}^{-2}$ daily, and Sb administered at three dose levels (200 mg daily, $200 \mathrm{mg} \mathrm{BID,} \mathrm{and} 400 \mathrm{mg}$ BID) starting on day 8 of RT. Thirty days after the end of RT, patients received monthly TMZ (150-200 $\mathrm{mg} \mathrm{m}^{-2}$ D1-5/28) and Sb (400 mg BID). Pharmacokinetic (PK) analyses were performed on day 8 (TMZ) and on day 21 (TMZ\&Sb) (Clinicaltrials ID: NCT00884416).

Results: The MTD of Sb was established at $200 \mathrm{mg}$ BID. Dose-limiting toxicities included thrombocytopenia (two patients), diarrhoea (one patient) and hypercholesterolaemia (one patient). Sb administration did not affect the mean area under the curve $(0-24)$ and mean $C_{\max }$ of TMZ and its metabolite 5-amino-imidazole-4-carboxamide (AIC). $T_{\max }$ of both TMZ and AIC was delayed from 0.75 (TMZ alone) to $1.5 \mathrm{~h}$ (combined TMZ/Sb). The median progression-free survival was 7.9 months ( $95 \%$ confidence interval (Cl): 5.4-14.55), and the median overall survival was 17.8 months (95\% Cl: 14.7-25.6).

Conclusions: Although Sb can be combined with RT and TMZ, significant side effects and moderate outcome results do not support further clinical development in malignant gliomas. The robust PK data of the TMZ/Sb combination could be useful in other cancer settings.

Most patients with glioblastoma (GBM) are currently treated with maximal safe resection followed by concomitant radiation therapy (RT) and temozolomide (TMZ) followed by adjuvant TMZ (Stupp et al, 2005). Despite some long-term benefit obtained in a small fraction of patients with this combined treatment, the median overall survival remains poor, at 14 months only (Stupp et al, 2005). Strategies to improve this outcome are desperately needed.
One attractive option is to explore the potential of drugs targeting intracellular pathways involved in gliomagenesis.

Sorafenib (Sb) (Nexavar) was initially developed as a specific inhibitor of the serine/threonine Raf kinase (Wilhelm et al, 2004) and has been approved by the US Food and Drug Administration for the treatment of patients with kidney cancer and hepatocellular carcinoma (Kane et al, 2006; Llovet et al, 2008). Further in vitro 
and in vivo studies showed that $\mathrm{Sb}$ targets multiple kinases, including vascular endothelial growth factor receptor-2 (VEGFR), VEGFR-3, Flt3, c-RAF, wild type and V599E mutant B-Raf, platelet-derived growth factor receptor $\beta$ (PDGFR $\beta)$, c-KIT, fibroblast growth factor receptor $1, \mathrm{p} 38 \alpha$ and RET (Liu et al, 2006). Thus, the cellular consequences of $\mathrm{Sb}$ are diverse (promotion of apoptosis, inhibition of tumour cell proliferation and angiogenesis, etc.), possibly leading to tumour growth arrest by targeting both tumour cells and blood vessels.

In the case of malignant glioma, several pathways in tumour and endothelial cells have key roles in disease progression and resistance to treatment. High levels of vascular endothelial growth factor (VEGF) and VEGF receptors are frequently observed (Salmaggi et al, 2003), PDGFR is often activated (Hermanson et al, 1992; Shih et al, 2004; Martinho et al, 2009), and up to $30 \%$ of patients carry an amplicon on chromosome 4q12 comprising the VEGFR2, PDGFR- $\alpha$ and KIT genes (Joensuu et al, 2005; Puputti et al, 2006; Holtkamp et al, 2007). In addition, although mutations in Ras or Raf are rare, the MAPK pathway is frequently activated, leading to poor prognosis (Davies et al, 2002). Altogether, several kinases involved in glioma progression are potentially targeted by $\mathrm{Sb}$, which therefore appears as a very attractive drug candidate to be tested.

The synergistic mode of action of the association of Sb not only with TMZ but also with RT is supported by experimental and clinical observations: combined with or following RT, Sb was shown to induce cell cycle arrest and a reduction in colonyforming units, as well as a delay in tumour growth in vivo in animal models (Plastaras et al, 2007). More recent data confirmed that $\mathrm{Sb}, \mathrm{TMZ}$ and RT synergistically reduced the tumour cell viability (Den et al, 2012), suggesting that the optimal benefit of this drug may be reached by combining it with RT (Dal Lago et al, 2008). Here we report the results of a phase I study of Sb combined with TMZ and RT in the upfront management of malignant glioma.

\section{MATERIALS AND METHODS}

Patient selection. Patients with newly diagnosed high-grade glioma (WHO grade III or GBM) for whom treatment with RT and TMZ was considered medically reasonable were eligible for inclusion in this study. Eligibility criteria further included age $\geqslant 18$ years, ECOG performance status $0-2$ and a life expectancy of at least 3 months. Patients were also required to have adequate renal, hepatic, cardiac and bone marrow function and to be on stable or decreasing dose of steroids in the 2 weeks prior to enrolment. All patients with reproductive potential were required to use effective birth control. Patients on stable anticoagulation therapy were allowed to enter the study. Given the primary aim of this phase I study, O6-methylguanine DNA-methyltransferase gene (MGMT) determination was performed in all patients but was not used as the selection or stratification criterion.

Exclusion criteria included having previous or current malignancies at other sites (with the exception of cervical carcinoma in situ, non melanoma carcinoma of the skin, superficial bladder tumour (Ta, Tis and $\mathrm{T} 1$ ) or any cancer curatively treated $>3$ years prior to study entry), serious medical or psychiatric illness that might interfere with the prescribed treatment, history of HIV infection, chronic hepatitis $\mathrm{C}$ or $\mathrm{B}$, having had organ allograft, renal dialysis, as well as prior exposure to Ras pathway inhibitors. Of note, in our institution, all brain tumour patients are treated exclusively with non-enzyme-inducing anti-seizure medication.

This investigator-driven study was developed and written at the Geneva University Hospitals. All patients provided written informed consent in accordance with institutional guidelines.
Approval was obtained from the Institutional Review Board of the University Hospitals of Geneva and the study was conducted in accordance with Good Clinical Practice Guidelines and the Declaration of Helsinki. The trial was registered as NCT00884416 on clinicaltrials.gov.

Study design. The study was a classical $3+3$ design, phase I, single-arm, single-centre study conducted to establish the maximum tolerated dose (MTD) of Sb in conjunction with TMZ and concurrent RT in patients with newly diagnosed high-grade gliomas (Le Tourneau et al, 2009). A minimum of three patients were included at each dose level. If none of the patients experienced a dose-limiting toxicity (DLT) until the end of week 10 (completion of RT and a 4 week break period), the next dose level was opened. If one patient had a DLT, three additional patients were enrolled at that dose level. If no additional patients had a DLT until the end of week 10, then the dose level was increased. If one or more of the additional patients had a DLT (therefore two or more out of six patients), then that dose level was deemed to be too toxic and an additional three patients were accrued to the prior dose level if only three patients had been enrolled. If well tolerated, this dose level would be documented as being the MTD.

Study outcomes. The primary objectives of this study were to determine the safety profile and tolerability of $\mathrm{Sb}$ when administered in conjunction with TMZ and RT and to establish the MTD of this combination. Secondary objectives were to evaluate pharmacokinetics (PKs), tumour response and survival.

Treatment plan and dosing levels. The phase I part of the study was defined as the period of concurrent treatment with RT, TMZ and $\mathrm{Sb}$ as well as the following 4 -week period, where patients were off treatment. The maintenance phase was defined as the period covering the six cycles of maintenance TMZ and Sb. As concurrent administration of $\mathrm{Sb}$ and TMZ without RT had previously been described in patients with melanoma (Amaravadi et al, 2009), this treatment phase was not considered to be a part of the phase I study and $\mathrm{Sb}$ was administered at a fixed level of $400 \mathrm{mg}$ twice daily (BID).

Radiation therapy consisted of a conventionally fractionated regimen to a total dose of $60 \mathrm{~Gy}$, administered in 30 daily fractions of $2 \mathrm{~Gy}$, with or without volumetric modulated arc therapy. Target volume definition was based on pre- and postoperative MRI with mandatory coregistration (fusion) of the MRI scan and the planning CT. Radiation therapy was delivered in accordance with Radiation Therapy Oncology Group guidelines and dose constraints. Standard dose constraints were used for normal structures. All patients were required to start treatment within 6 weeks of surgery. Temozolomide was administered continuously at a dose of $75 \mathrm{mg} \mathrm{m}^{-2}$ concurrently with RT, starting on the first day of RT, and administered daily for up to 42 days or until the end of RT.

Three dose levels for $\mathrm{Sb}$ were planned as follows: cohort 1 received a single daily oral dose of $200 \mathrm{mg}$, cohort 2 received $200 \mathrm{mg} \mathrm{Sb} \mathrm{BID}$ and cohort 3 received $400 \mathrm{mg}$ BID. In the concurrent phase, $\mathrm{Sb}$ was started at the pre-specified dose level on day 8 after the start of RT and TMZ.

After a break of 4 weeks, patients were treated in the maintenance phase with TMZ $\left(150 \mathrm{mg} \mathrm{m}^{-2}\right.$ on $\mathrm{d} 1-5$ for the first cycle of 28 days) followed for a total of up to six cycles of TMZ given at $200 \mathrm{mg} \mathrm{m}^{-2}$ on $\mathrm{d} 1-5 / 28$ if the first cycle was tolerated without significant side effects. Sorafenib was restarted on day 1 of the first cycle at $400 \mathrm{mg}$ BID regardless of the dose level in the concurrent phase. Treatment was continued until evidence of progressive disease or excessive toxicity, patient's refusal to continue or if the treating physician felt termination to be in the patient's best interest. 
Safety. All patients who received at least one dose of Sb were evaluated for safety. Patients were evaluated continuously throughout the study for physical assessment, vital signs and incidence of adverse events, DLTs and abnormal laboratory values.

Toxicities were graded according to the National Cancer Institute's Common Terminology Criteria for Adverse Events, version 3.0. The DLTs for this study were defined as any of the following adverse events related to the combination treatment: grade 4 thrombocytopenia, grade 4 neutropenia lasting over 7 days, grade 3 or 4 febrile neutropenia, or any grade 3 or 4 nonhaematologic toxicities except alopecia, nausea, vomiting, hypophosphataemia, fatigue or fever that can be rapidly controlled by adequate measures.

Pharmacokinetics. Pharmacokinetic profiles of TMZ were determined on day 7 (prior to the initiation of $\mathrm{Sb}$ ) and day 21 (after 14 days of treatment with $\mathrm{Sb}$ ) of the concurrent treatment. On these days, plasma samples were collected prior to the ingestion of TMZ and $0.25,0.5,0.75,1,1.5,2,3,4,6,8,12$ and $24 \mathrm{~h}$ thereafter to determine the concentrations of $\mathrm{TMZ}$ and of its metabolite 5-amino-imidazole-4-carboxamide (AIC). For the determination of TMZ and AIC, blood samples ( $5 \mathrm{ml}$ aliquots) were collected into a tube containing ammonium heparin, and centrifuged at $2000 \times \mathbf{g}$ for $5 \mathrm{~min}$ at $+4^{\circ} \mathrm{C}$ to separate the plasma. Two $\mathrm{ml}$ of the plasma was then transferred to polypropylene tubes containing $0.2 \mathrm{ml}$ of $1 \mathrm{~m}$ hydrochloric acid, mixed for $1 \mathrm{~min}$ and frozen (at $-70^{\circ} \mathrm{C}$ or lower) until assayed. Samples were kept in the dark and on ice at all times during manipulations. Temozolomide and AIC were quantified in plasma samples by liquid chromatography-mass spectrometry (LC-MS/MS). The lower limit of quantification (LOQ) was $5 \mu \mathrm{gl}^{-1}$ for TMZ and $10 \mu \mathrm{gl} 1^{-1}$ for AIC. Assays were performed at Bayer HealthCare, Berlin, Germany.

Plasma concentrations of $\mathrm{Sb}$ were also determined on day 21 prior to administration of $\mathrm{Sb}$, as well as $0.5,1,2,4,8,10$ and $12 \mathrm{~h}$ thereafter. Blood samples were centrifuged at $2000 \times \mathbf{g}$ for $10 \mathrm{~min}$ at $+4{ }^{\circ} \mathrm{C}$ and the plasma was then transferred to a polypropylene tube and frozen at $-20{ }^{\circ} \mathrm{C}$ until analysis. The determination of plasma concentrations of $\mathrm{Sb}$ was performed using a fully validated specific LC-MS/MS assay method with a LOQ of $0.01 \mathrm{mgl}^{-1}$ for $\mathrm{Sb}$. Assays were performed at Bayer HealthCare.

Pharmacokinetic parameters were derived by non-compartmental analysis, using WinNonlin v.4.1a. Primary PK parameters were $C_{\max }$ and area under the curve $(\mathrm{AUC})_{(0-12)}$ for $\mathrm{Sb}$, and $C_{\max }$ and $\mathrm{AUC}_{(0-24)}$ for TMZ. Secondary PK parameters assessed included $T_{\max }$ and $T_{1 / 2}$. Data are presented as arithmetic mean \pm s.d., except for $T_{\max }$, for which median and range are presented. Ratios of day 21 to day 7 PK parameters and $90 \%$ confidence interval (CI) were derived from geometric means.

MGMT promoter methylation status determination. The promoter methylation status of the MGMT was assessed on DNA isolated from paraffin-embedded tumour samples obtained at initial surgery. MDxHealth, Liège, Belgium, performed the test with quantitative methylation-specific PCR (Vlassenbroeck et al, 2008).

Efficacy. All patients who received at least one dose of RT and TMZ were assessed for tumour response based on MacDonald criteria. Time to treatment failure, event-free survival and overall survival were also assessed. Tumour measurements were performed at baseline, 4 weeks after completion of Sb/TMZ/RT treatment and every 2 months thereafter.

\section{RESULTS}

A total of 17 patients were enrolled from April 2009 to March 2011 in this dose escalation study: six in cohort 1, six in cohort 2 and three in cohort 3; two patients signed consent but had to be excluded because of neurological deterioration prior to start of treatment. The baseline demographics for all patients are shown in Table 1. All patients were diagnosed with GBM except one patient of cohort 2 (WHO grade III anaplastic oligoastrocytoma after pathological review). Seven patients had a complete or nearcomplete (over 90\%) resection, five patients had an incomplete resection $(<90 \%)$ and three patients (all in cohort 2 ) underwent

Table 1. Patient baseline characteristics

\begin{tabular}{|c|c|c|c|c|c|c|c|}
\hline Patient & Sex & $\begin{array}{l}\text { Age at } \\
\text { diagnosis }\end{array}$ & Diagnosis & $\begin{array}{l}\text { Type of } \\
\text { resection }\end{array}$ & $\begin{array}{l}\text { MGMT } \\
\text { Status }\end{array}$ & $\begin{array}{l}\text { ECOG } \\
\text { at inclusion }\end{array}$ & $\begin{array}{l}\text { Sorafenib adminstration in } \\
\text { phase I part }\end{array}$ \\
\hline Dose level 1 & & & & & & & $1 \mathrm{DLT}$ \\
\hline Patient 1 & M & 67.1 & GBM & Incomplete & Unmethylated & 0 & DLT (thrombocytopenia grade 4) \\
\hline Patient 2 & M & 37.3 & GBM & Complete & Invalid test & 0 & Completed \\
\hline Patient 3 & $\mathrm{~F}$ & 62.4 & GBM & Near complete & Unmethylated & 0 & Completed \\
\hline Patient 4 & $\mathrm{~F}$ & 64.0 & GBM & Incomplete & Unmethylated & 0 & Completed (pulmonary embolism, grade 4) \\
\hline Patient 5: screening failure & & & & & & & \\
\hline Patient 6 & M & 43.3 & GBM & Complete & Unmethylated & 0 & Completed \\
\hline Patient 7 & M & 54.6 & GBM & Incomplete & Unmethylated & 0 & Completed \\
\hline Dose level 2 & & & & & & & $1 \mathrm{DLT}$ \\
\hline Patient 8: screening failure & & & & & & & \\
\hline Patient 9 & $\mathrm{~F}$ & 61.7 & GBM & Near complete & Methylated & 0 & Completed \\
\hline Patient 10 & $\mathrm{~F}$ & 48.5 & GBM & Incomplete & Methylated & 0 & Completed \\
\hline Patient 11 & M & 62.5 & GBM & Biopsy & Invalid test & 1 & Completed \\
\hline Patient 15 & $\mathrm{~F}$ & 25.1 & GBM & Complete & Unmethylated & 0 & Completed \\
\hline Patient 16 & $\mathrm{~F}$ & 57.8 & GBM & Biopsy & Not determined & 0 & Completed \\
\hline Patient 17 & $\mathrm{~F}$ & 45.3 & OA grade 3 & Biopsy & Not determined & 0 & DLT (thrombocytopenia grade 4) \\
\hline Dose level 3 & & & & & & & 2 DLTs \\
\hline Patient 12 & $\mathrm{~F}$ & 41.2 & GBM & Near complete & Unmethylated & 0 & $\begin{array}{l}\text { Interrupted (pt's wish after hand-foot syndrome } \\
\text { grade 3) }\end{array}$ \\
\hline Patient 13 & $\mathrm{~F}$ & 47.8 & GBM & Incomplete & Methylated & 1 & $\begin{array}{l}\text { DLT (hypercholesterolaemia and } \\
\text { triglyceridaemia, grade 3) }\end{array}$ \\
\hline Patient 14 & $\mathrm{~F}$ & 69.9 & GBM & Complete & Unmethylated & 0 & DLT (diarrhoea grade 4) \\
\hline
\end{tabular}


biopsy only. All but two patients presented with an ECOG of 0 . Of note, given the risk of interaction with $\mathrm{Sb}$ and TMZ, none of the patients included in this study were treated with enzyme-inducing antiepileptic agents.

Adverse events and dose-limiting toxicities. The 17 patients enrolled in the study were evaluable for safety analyses (Table 2). All patients (100\%) experienced at least one treatment-related adverse event at any grade. Eleven patients (65\%) reported treatment-related adverse events of grade 3 or 4 . The most common toxicities were haematologic, fatigue and hand-foot skin reaction (HFSR). Hand-foot skin reaction was reported more frequently with higher doses of $\mathrm{Sb}$ (cohorts 2 and 3). A total of four patients developed DLTs: two cases of grade 4 thrombocytopenia (one in cohort 1 and one in cohort 2), one grade 3 hypercholesterolaemia and hypertriglyceridaemia, and one grade 3 diarrhoea (both in cohort 3). These toxicities failed to improve within the preset time frame and were evaluated to be definitely or probably linked to the combination of Sb with TMZ and/or RT. Thus, the recommended dose for $\mathrm{Sb}$ in conjunction with $\mathrm{RT}$ and daily TMZ ( $75 \mathrm{mg} \mathrm{m}^{-2}$ per day) was established at $200 \mathrm{mg}$ BID. Of note, all patients who did not develop DLTs completed the Sb and TMZ treatment of the concomitant phase of the protocol.

During the maintenance phase, 7 out of 17 patients did not restart Sb: 4 patients had developed DLTs during the initial phase, 2 patients withdrew their consent to participate to the maintenance phase of the trial, mainly because of non-DLT adverse reactions experienced during the initial phase, and 1 patient was taken off study because of tumour progression on the MRI performed 4 weeks after completion of concomitant RT/TMZ/Sb. Four additional patients prematurely stopped the $\mathrm{Sb}$ and TMZ treatments due to adverse events (grade 3 HFSR, grade 4 neutropenia, grade 4 liver enzyme abnormalities and grade 3 hypertriglyceridaemia, and grade 4 thrombocytopenia).

Pharmacokinetic studies. Pharmacokinetic parameters were assessed in all 12 patients of cohorts 1 and 2 and in two patients of cohort 3. Analysis of PKs for Sb was performed on day 21 of the combined treatment $(\mathrm{RT} / \mathrm{TMZ} / \mathrm{Sb})$. Mean $\mathrm{AUC}_{(0-12)}\left(\mathrm{mghl}^{-1}\right)$ was $23.0 \pm 10.5,40.9 \pm 25.2$ and $63.8 \pm 4.3$, and mean $C_{\max }$ was $3.1 \pm 1.8, \quad 6.3 \pm 4.8$ and $7.24 \pm 0.05$, for cohorts 1,2 and 3 , respectively. The concentration of $\mathrm{Sb}$ in plasma remained stable over at least $12 \mathrm{~h}$.

\begin{tabular}{|c|c|c|c|c|}
\hline Toxicity & $\begin{array}{c}\text { Grade } \\
1-2, \\
n(\%)\end{array}$ & $\begin{array}{c}\text { Grade } \\
3, n(\%)\end{array}$ & $\begin{array}{c}\text { Grade } \\
4, n(\%)\end{array}$ & $\begin{array}{l}\text { Grade } \\
5, n(\%)\end{array}$ \\
\hline Haematological-Thrombocytopenia & $1(6.6 \%)$ & $3(20 \%)$ & $2(13.3 \%)$ & 0 \\
\hline Haematological-Lymphopenia & 0 & $1(6.6 \%)$ & $2(13.3 \%)$ & 0 \\
\hline Haematological-Neutropenia & $1(6.6 \%)$ & $1(6.6 \%)$ & $1(6.6 \%)$ & 0 \\
\hline Pulmonary embolism & 0 & 0 & $1(6.6 \%)$ & 0 \\
\hline Cutaneous-Skin rash & $6(40 \%)$ & 0 & 0 & 0 \\
\hline Cutaneous-Hand-foot syndrome & $4(26.6 \%)$ & $2(13.2 \%)$ & 0 & 0 \\
\hline Dyslipidemia & $1(6.6 \%)$ & $1(6.6 \%)$ & 0 & 0 \\
\hline Diarrhoea & $1(6.6 \%)$ & $1(6.6 \%)$ & 0 & 0 \\
\hline Constipation & 0 & $1(6.6 \%)$ & 0 & 0 \\
\hline Hypertension & $2(13.3 \%)$ & $2(13.3 \%)$ & 0 & 0 \\
\hline Heart rate abnormalities & $4(26.6 \%)$ & $1(6.6 \%)$ & 0 & 0 \\
\hline Fatigue & 3 (20\%) & 2 (13.3\%) & 0 & 0 \\
\hline
\end{tabular}

Regarding TMZ, comparison of PK parameters from day 7 (TMZ in the absence of $\mathrm{Sb}$ ) and day 21 (TMZ plus Sb) showed that $\mathrm{Sb}$ administration at any of the studied doses had no effect on both mean $\mathrm{AUC}_{(0-24)}$ and mean $C_{\max }$ of TMZ and its metabolite AIC (Figure $1 \mathrm{a}$ and $\mathrm{b}$ and Table 3 ). The narrow ranges of all values confirm the limited inter-individual variability of bioavailability when both drugs are taken together. Temozolomide half-life was also unaffected by $\mathrm{Sb}$, averaging $1.6-1.7 \mathrm{~h}$ for all cohorts with or without Sb. AIC half-life was also unaffected by Sb (Table 3). The only PK parameter that was slightly affected was TMZ $T_{\max }$, which was slightly prolonged from 0.75 to $1.5 \mathrm{~h}$ with combined $\mathrm{Sb} / \mathrm{TMZ}$ at the MTD in cohort 2 compared with TMZ alone (Table 3).

Response to treatment. The best responses observed in this study were 2 partial responses (cohorts 1 and 2, 13.3\%) and 10 stable diseases (four in cohort 1 , three in cohort 2 and three in cohort 3 , $66.6 \%$ ). Of note, 2 of these 10 patients maintained complete responses following complete resection (one patient in cohorts 1 and 2, each). One patient of cohort 1 and two patients of cohort 2 showed progressive disease (20\% of all patients).

Of note, seven patients ( $46 \%$ of all patients) presented with pseudoprogression on the first MRI performed 4 weeks after completion of RT. For this study, pseudoprogression was defined as a radiological progression of the lesion in the first MRI performed after completion of RT with a subsequent MRI that showed either stable disease (six patients in our study) or partial remission (one patient). The median progression-free survival (PFS)
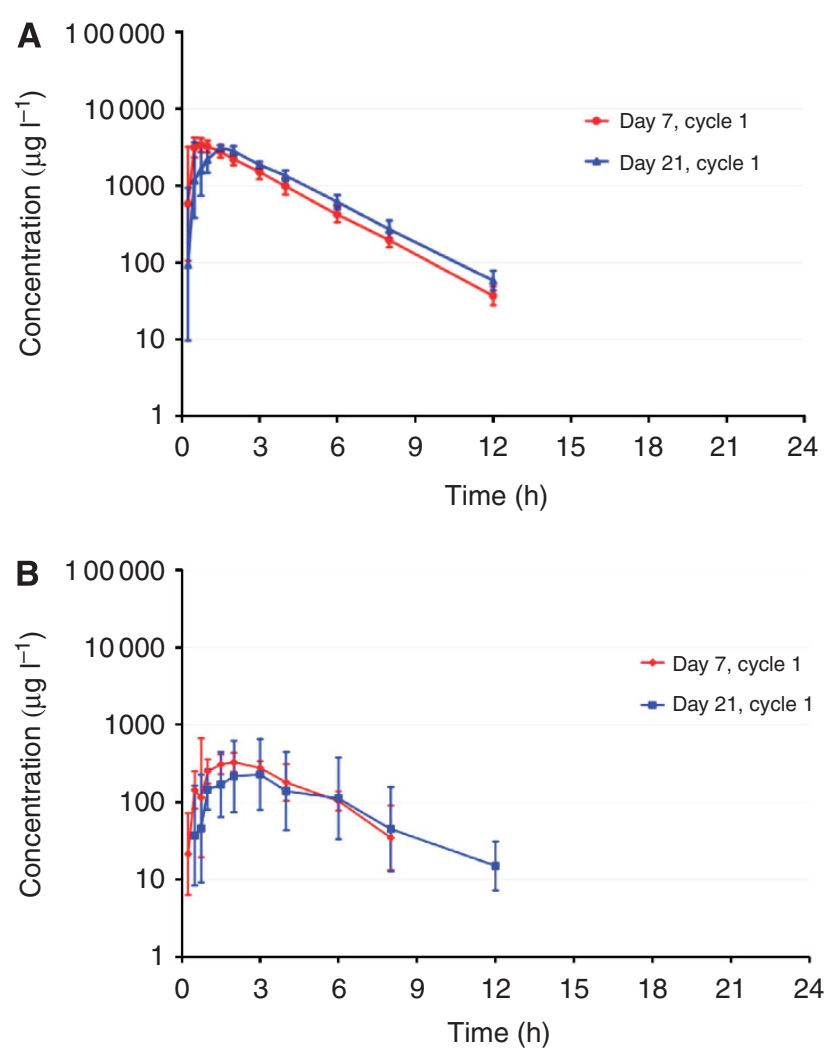

Figure 1. (A) Plasma concentrations of $T M Z$ following multiple doses of $75 \mathrm{mg} \mathrm{m}^{-2}$ of TMZ without (Day 7, Cycle 1) and after concomitant treatment (Day 21, Cycle 1) with multiple oral doses of $200 \mathrm{mg}$ BID sorafenib in patients of cohort 2 (geometric means, geometric SD; $n=6$ ). (B) Plasma concentrations of AIC following multiple doses of $75 \mathrm{mg} \mathrm{m}^{-2}$ of TMZ without (Day 7, Cycle 1) and after concomitant treatment (Day 21, Cycle 1) with multiple oral doses of $200 \mathrm{mg}$ BID sorafenib in patients of cohort 2 (geometric means, geometric $\mathrm{SD} ; n=6)$. 
was 7.9 months (95\% CI: 5.4-14.55) and the 6-month PFS was $86.7 \%$. Of the 13 patients who developed progressive disease, $5(38 \%)$ did not receive any further treatment, mainly because of high kinetics of tumour growth and poor performance status. Five patients $(38 \%)$ received a single additional line of treatment (single bevacizumab in four patients, re-resection followed by bevacizumab: one patient). Of those patients, one is still on treatment. One patient was treated with two further lines of treatment (dose-dense TMZ followed by bevacizumab) and two patients have received three further lines of treatment (dose-dense TMZ/bevacizumab/CCNU and bevacizumab/CCNU/metronomic TMZ, respectively). Of note, 2 patients out of 17 (12\%) developed impressive leptomeningeal dissemination of the GBM (confirmed by CSF cytology) following treatment of recurrent disease with bevacizumab (Figure 2). The median overall survival was 17.8 months (95\% CI: 14.7-25.6).

\section{DISCUSSION}

When combined with RT and continuous administration of TMZ ( $75 \mathrm{mg} \mathrm{m}^{-2}$ per day), the MTD of Sb was established at $200 \mathrm{mg}$ twice daily in this study. The main toxicity was grade $3 / 4$ thrombocytopenia, with an increased incidence in our study, compared with what has been reported for TMZ or Sb alone (43.3\% vs $19 \%$ and $<2 \%$, respectively (Andenmatten et al, 2013)). In contrast, the incidences of neutropenia, lymphopenia, skin rash or hand-foot skin reaction were similar to those reported with either TMZ or Sb alone (Stupp et al, 2005; Escudier et al, 2007; Llovet et al, 2008). Other toxicities leading to the MTD were intractable diarrhoea, as well as grade 3 hypertriglyceridaemia and hypercholesterolaemia. Whether the risk of this last toxicity, which is a rare side effect observed with TMZ (investigator's brochure), is increased by the combined administration of $\mathrm{Sb}$ and TMZ is unknown.
Another trial also investigated the combination of Sb with initial $\mathrm{RT}$ or re-irradiation in conjunction with TMZ in patients with de novo or recurrent gliomas (Den et al, 2012). The MTD for Sb was also suggested to be $200 \mathrm{mg}$ twice daily, concurring with our data. However, this study had important limitations because of a complex design leading to various RT durations and doses, and the inclusion of patients in different settings. Consequently, the majority of patients were exposed to minimal amounts of Sb. Indeed, over $60 \%$ of patients discontinued treatment prior to the end of radiotherapy. Moreover, the doses of RT considerably varied (35 Gy stereotactic vs $60 \mathrm{~Gy}$ in 30 fractions) and the treatment period extended between 2-6 weeks, further shortening the exposition to the combination treatment, with the risk of missing potential toxicities that may arise following prolonged exposure to the therapeutic agents. In contrast, in our study, over $78 \%$ of the total planned doses of $\mathrm{Sb}$ have been administered during the concomitant phase, definitively establishing the Sb MTD at $200 \mathrm{mg}$ twice daily.

Another finding from our study is that the addition of Sb did not significantly change the plasma concentrations of TMZ. Thus, there is no pharmacological impediment to combining Sb, TMZ and irradiation. However, it is interesting to note that at the dose level of $200 \mathrm{mg}$ Sb BID, $T_{\max }$ was delayed by $\sim 0.75 \mathrm{~h}$ when TMZ and $\mathrm{Sb}$ were co-administered. This effect was not observed at the dose of $200 \mathrm{mg}$ per day, potentially because the concentration of $\mathrm{Sb}$ was too small to induce this interaction. At the dose of $400 \mathrm{mg} \mathrm{Sb}$ BID, two patients only were evaluated, complicating the interpretation of the results from cohort 3 . This delay in $T_{\max }$ may however be clinically relevant, as TMZ is routinely administered $1 \mathrm{~h}$ before irradiation so that the peak plasma TMZ concentration coincides with the administration of RT.

Although this study was not powered to determine the effects on PFS or radiographic response rate, the results observed in this phase I study suggest that addition of Sb to RT and TMZ does not result in significant improvement of PFS, when compared with the

Table 3. Pharmacokinetic parameters of TMZ and its metabolite AIC after administration of TMZ $75 \mathrm{mg} \mathrm{m}^{-2}$ per day without (day 7 ) and with varying doses of $\mathrm{Sb}$ (day 21)

\begin{tabular}{|c|c|c|c|c|c|c|}
\hline & \multicolumn{2}{|c|}{ Cohort 1, $n=6$} & \multicolumn{2}{|c|}{ Cohort 2, $n=6$} & \multicolumn{2}{|c|}{ Cohort $3, n=2$} \\
\hline & TMZ & AIC & TMZ & AIC & TMZ & $\mathrm{AIC}$ \\
\hline \multicolumn{7}{|c|}{$C_{\max }\left(\mathrm{mgl}^{-1}\right)$, mean $\pm \mathrm{s} . \mathrm{d}$} \\
\hline $\begin{array}{l}\text { TMZ alone (day 7) } \\
\text { TMZ \& Sb (day 21) } \\
\text { Ratio (day 21/day 7) } \\
90 \% \mathrm{Cl}\end{array}$ & $\begin{array}{c}6.1 \pm 1.7 \\
6.7 \pm 3.1 \\
1.02 \\
0.80-1.31\end{array}$ & $\begin{array}{c}0.37 \pm 0.08 \\
0.32 \pm 0.08 \\
0.87 \\
0.79-0.96\end{array}$ & $\begin{array}{c}4.1 \pm 0.9 \\
3.9 \pm 1.2 \\
0.94 \\
0.71-1.26\end{array}$ & $\begin{array}{c}0.33 \pm 0.09 \\
0.31 \pm 0.15 \\
0.76 \\
0.38-1.50\end{array}$ & $\begin{array}{c}4.4 \pm 1.6 \\
3.6 \pm 1.4 \\
0.8 \\
0.71-0.91\end{array}$ & $\begin{array}{c}0.40 \pm 0.09 \\
0.21 \pm 0.25 \\
0.31 \\
0.001-1.88\end{array}$ \\
\hline \multicolumn{7}{|c|}{$A \cup C(0-24)\left(\mathrm{mg} \mathrm{h}^{-1}\right)$, mean \pm s.d. } \\
\hline $\begin{array}{l}\text { TMZ alone (day 7) } \\
\text { TMZ \& Sb (day 21) } \\
\text { Ratio (day 21/day 7) } \\
90 \% \mathrm{Cl}\end{array}$ & $\begin{array}{c}11.7 \pm 1.9 \\
13.3 \pm 2.42 \\
1.14 \\
1.04-1.24\end{array}$ & $\begin{array}{c}1.58 \pm 0.48 \\
1.70 \pm 0.47 \\
1.08 \\
1.00-1.18\end{array}$ & $\begin{array}{c}10.8 \pm 1.4 \\
11.9 \pm 0.96 \\
1.1 \\
0.97-1.25\end{array}$ & $\begin{array}{c}1.64 \pm 0.31 \\
1.51 \pm 0.79 \\
0.73 \\
0.35-1.52\end{array}$ & $\begin{array}{c}10.5 \pm 0.5 \\
10.3 \pm 1.89 \\
0.97 \\
0.52-1.81\end{array}$ & $\begin{array}{l}1.70 \pm 0.45 \\
\text { n.d. } \\
\text { n.d. }\end{array}$ \\
\hline \multicolumn{7}{|c|}{$T_{\max }(\mathrm{h})$, median (range) } \\
\hline $\begin{array}{l}\text { TMZ alone (day 7) } \\
\text { TMZ \& Sb (day 21) }\end{array}$ & $\begin{array}{l}0.25(0.25-1.50) \\
0.50(0.25-2.00)\end{array}$ & $\begin{array}{l}1.75(1.50-2.00) \\
2.00(0.75-3.00)\end{array}$ & $\begin{array}{l}0.75(0.25-1.50) \\
1.50(0.25-2.00)\end{array}$ & $\begin{array}{l}1.75(1.50-4.00) \\
2.00(1.50-3.00)\end{array}$ & $\begin{array}{l}0.63(0.50-0.75) \\
0.88(0.75-1.00)\end{array}$ & $\begin{array}{l}2.00(2.00-2.00) \\
2.00(2.00-2.00)\end{array}$ \\
\hline \multicolumn{7}{|c|}{$T_{1 / 2}(h)$, mean \pm s.d. } \\
\hline $\begin{array}{l}\text { TMZ alone (day 7) } \\
\text { TMZ \& Sb (day 21) }\end{array}$ & $\begin{array}{l}1.59 \pm 0.09 \\
1.71 \pm 0.07\end{array}$ & $\begin{array}{l}1.71 \pm 0.21 \\
1.99 \pm 0.11\end{array}$ & $\begin{array}{l}1.69 \pm 0.08 \\
1.77 \pm 0.16\end{array}$ & $\begin{array}{l}2.37 \pm 0.92 \\
2.56 \pm 1.48\end{array}$ & $\begin{array}{l}1.78 \pm 0.19 \\
1.65 \pm 0.02\end{array}$ & $\begin{array}{l}2.09 \pm 0.26 \\
2.29 \pm 0.45\end{array}$ \\
\hline
\end{tabular}




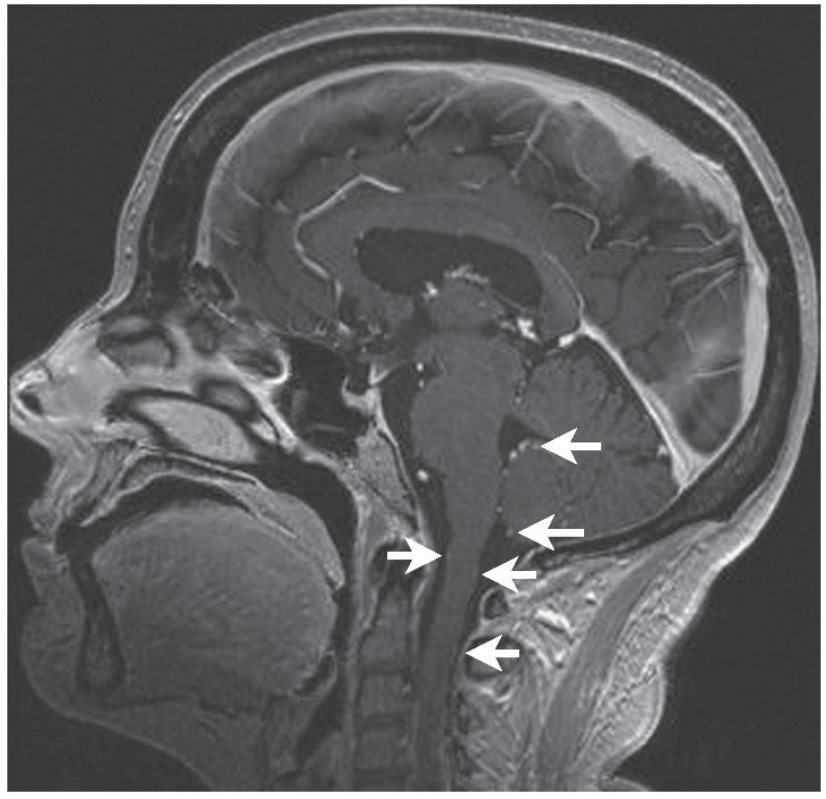

Figure 2. Two patients developed leptomeningeal dissemination of GBM following treatment with RT/TMZ/Sb followed by bevacizumab treatment at recurrence: T1 gadolinium sequence of patient 10 showing extensive leptomeningeal dissemination (arrows).

phase III landmark trial (7.9 vs 6.9 months) (Stupp et al, 2005). There are some potential reasons for these disappointing results. Although the plasma levels of both TMZ and Sb were within the expected range (Lee et al, 2012), CNS distribution studies have shown that CNS penetration of $\mathrm{Sb}$ is limited, predominantly by the breast cancer resistance protein (ABCG2/BRCP), a member of the ATP-binding cassette transporters (Agarwal et al, 2011). Such properties may also contribute to the disappointing results obtained in other studies combining $\mathrm{Sb}$ and TMZ without irradiation for patients with recurrent GBM or as standalone maintenance treatment following RT (Hainsworth et al, 2010; Reardon et al, 2011; Lee et al, 2012). Moreover, the addition of TMZ to RT has been shown to favour the induction of an exaggerated reaction to $\mathrm{RT}$, which has been termed pseudoprogression (Taal et al, 2008).

Interestingly, in our cohort, the median overall survival of 17.8 months was unexpectedly longer than the OS observed in the landmark EORTC trial (14.2 months) and in a recent phase II trial that evaluated the role of bevacizumab and everolimus in addition to RT and TMZ as upfront treatment for GBM (13.9 months) (Hainsworth et al, 2012). Our results are, however, in line with a number of phase II trials evaluating the upfront addition of bevacizumab to RT and TMZ, which have reported a median OS of 19.6, 21.3 and 23 months (Lai et al, 2011; Vredenburgh et al, 2012). Whether this moderate rise in overall survival may be partially related to the addition of $\mathrm{Sb}$, reflects the overall improvement observed with the current multidisciplinary management of patients with high-grade gliomas or is an unexpected patient selection bias (especially given the better overall performance status of the patients enrolled in this study) cannot be determined without a phase III study. However, the minimal response rates along with the disappointing PFS results obtained in the present study did not support this further step of clinical development.

Also of concern was the impressive leptomeningeal dissemination observed in two patients following salvage treatment with bevacizumab. It remains unclear whether this observation is related to $\mathrm{Sb}$, but this possibility cannot be excluded with certainty. Inhibition of VEGF signalling has been shown to lead to a pro-invasive phenotype in mouse GBM models and in a subset of
GBM patients treated with bevacizumab (Lu et al, 2012). Given the extended VEGF inhibition through $\mathrm{Sb}$ and bevacizumab, one may hypothesise that activation of alternative pathways may select for more aggressive and invasive tumour phenotypes.

In conclusion, the PK results of this study definitely show that TMZ and Sb can be combined without major pharmacological interaction. However, the importance of side effects and the rather poor outcome results obtained in patients with newly diagnosed high-grade glioma do not support the further clinical exploration of this combined modality (RT/TMZ/Sb).

\section{ACKNOWLEDGEMENTS}

We are indebted to the patients and their families for agreeing to participate in this trial. This work was supported by an unrestricted educational grant from Bayer, Zurich, Switzerland, which also provided the study drugs. Bayer had no role in (a) the design of the study, (b) the data collection, analysis and interpretation and (c) the preparation of the manuscript, and had no rights to approve, delay or disapprove of publication of the work.

\section{CONFLICT OF INTEREST}

Andreas F Hottinger: advisory board for MSD, Switzerland and Roche, Switzerland, and honoraria from the speakers bureau from MSD, International. Thomas Hundsberger: advisory boards for MSD, Switzerland and Roche, Switzerland. Pierre-Yves Dietrich: advisory board for Bayer, Switzerland. The other authors declare no conflict of interest.

\section{AUTHOR CONTRIBUTIONS}

Conception and design: AFH, ABo, PYD. Development of methodology: AFH, PYD. Acquisition of data: AFH, AB, VE, DS, ND, MIV, KS, DCW. Analysis and interpretation of data: AFH, TH, PYD. Writing, review and/or revision of the manuscript: AFH, $\mathrm{AB}, \mathrm{VE}, \mathrm{DS}, \mathrm{ND}, \mathrm{MIV}, \mathrm{TH}, \mathrm{NM}, \mathrm{KS}, \mathrm{DCW}, \mathrm{ABo}, \mathrm{PYD}$. Administrative, technical or material support: AFH, NM, PYD. Study supervision: AFH, PYD.

\section{REFERENCES}

Agarwal S, Sane R, Ohlfest JR, Elmquist WF (2011) The role of the breast cancer resistance protein (ABCG2) in the distribution of sorafenib to the brain. J Pharmacol Exp Ther 336: 223.

Amaravadi RK, Schuchter LM, McDermott DF, Kramer A, Giles L, Gramlich K, Carberry M, Troxel AB, Letrero R, Nathanson KL, Atkins MB, O’Dwyer PJ, Flaherty KT (2009) Phase II trial of temozolomide and sorafenib in advanced melanoma patients with or without brain metastases. Clin Cancer Res 15: 7711.

Andenmatten R, Erdogan S, Schwander P, Frei S, Borer D (2013) Compendium Suisse des médicaments.

Dal Lago L, D'Hondt V, Awada A (2008) Selected combination therapy with sorafenib: a review of clinical data and perspectives in advanced solid tumors. Oncologist 13: 845.

Davies H, Bignell GR, Cox C, Stephens P, Edkins S, Clegg S, Teague J, Woffendin H, Garnett MJ, Bottomley W, Davis N, Dicks E, Ewing R, Floyd Y, Gray K, Hall S, Hawes R, Hughes J, Kosmidou V, Menzies A, Mould C, Parker A, Stevens C, Watt S, Hooper S, Wilson R, Jayatilake H, Gusterson BA, Cooper C, Shipley J, Hargrave D, Pritchard-Jones K, Maitland N, Chenevix-Trench G, Riggins GJ, Bigner DD, Palmieri G, Cossu A, Flanagan A, Nicholson A, Ho JW, Leung SY, Yuen ST, Weber BL, Seigler HF, Darrow TL, Paterson H, Marais R, Marshall CJ, Wooster R, Stratton MR, Futreal PA (2002) Mutations of the BRAF gene in human cancer. Nature 417: 949. 
Den RB, Kamrava M, Sheng Z, Werner-Wasik M, Dougherty E, Marinucchi M, Lawrence YR, Hegarty S, Hyslop T, Andrews DW, Glass J, Friedman DP, Green MR, Camphausen K, Dicker AP (2012) A phase I study of the combination of sorafenib with temozolomide and radiation therapy for the treatment of primary and rRecurrent high-grade gliomas. Int $J$ Radiat Oncol Biol Phys 85: 321-328.

Escudier B, Eisen T, Stadler WM, Szczylik C, Oudard S, Siebels M, Negrier S, Chevreau C, Solska E, Desai AA, Rolland F, Demkow T, Hutson TE, Gore M, Freeman S, Schwartz B, Shan M, Simantov R, Bukowski RM (2007) Sorafenib in advanced clear-cell renal-cell carcinoma. N Engl J Med 356: 125.

Hainsworth JD, Ervin T, Friedman E, Priego V, Murphy PB, Clark BL, Lamar RE (2010) Concurrent radiotherapy and temozolomide followed by temozolomide and sorafenib in the first-line treatment of patients with glioblastoma multiforme. Cancer 116: 3663.

Hainsworth JD, Shih KC, Shepard GC, Tillinghast GW, Brinker BT, Spigel DR (2012) Phase II study of concurrent radiation therapy, temozolomide, and bevacizumab followed by bevacizumab/everolimus as first-line treatment for patients with glioblastoma. Clin Adv Hematol Oncol 10: 240.

Hermanson M, Funa K, Hartman M, Claesson-Welsh L, Heldin CH, Westermark B, Nister M (1992) Platelet-derived growth factor and its receptors in human glioma tissue: expression of messenger RNA and protein suggests the presence of autocrine and paracrine loops. Cancer Res 52: 3213.

Holtkamp N, Ziegenhagen N, Malzer E, Hartmann C, Giese A, von Deimling A (2007) Characterization of the amplicon on chromosomal segment $4 \mathrm{q} 12$ in glioblastoma multiforme. Neuro Oncol 9: 291.

Joensuu H, Puputti M, Sihto H, Tynninen O, Nupponen NN (2005) Amplification of genes encoding KIT, PDGFRalpha and VEGFR2 receptor tyrosine kinases is frequent in glioblastoma multiforme. J Pathol 207: 224.

Kane RC, Farrell AT, Saber H, Tang S, Williams G, Jee JM, Liang C, Booth B, Chidambaram N, Morse D, Sridhara R, Garvey P, Justice R, Pazdur R (2006) Sorafenib for the treatment of advanced renal cell carcinoma. Clin Cancer Res 12: 7271

Lai A, Tran A, Nghiemphu PL, Pope WB, Solis OE, Selch M, Filka E, Yong WH, Mischel PS, Liau LM, Phuphanich S, Black K, Peak S, Green RM, Spier CE, Kolevska T, Polikoff J, Fehrenbacher L, Elashoff R, Cloughesy T (2011) Phase II study of bevacizumab plus temozolomide during and after radiation therapy for patients with newly diagnosed glioblastoma multiforme. J Clin Oncol 29: 142.

Le Tourneau C, Lee JJ, Siu LL (2009) Dose escalation methods in phase I cancer clinical trials. J Natl Cancer Inst 101: 708.

Lee EQ, Kuhn J, Lamborn KR, Abrey L, Deangelis LM, Lieberman F, Robins HI, Chang SM, Yung WK, Drappatz J, Mehta MP, Levin VA, Aldape K, Dancey JE, Wright JJ, Prados MD, Cloughesy TF, Gilbert MR, Wen PY (2012) Phase I/II study of sorafenib in combination with temsirolimus for recurrent glioblastoma or gliosarcoma: North American Brain Tumor Consortium study 05-02. Neuro Oncol 14: 1511-1518.

Liu L, Cao Y, Chen C, Zhang X, McNabola A, Wilkie D, Wilhelm S, Lynch M, Carter C (2006) Sorafenib blocks the RAF/MEK/ERK pathway, inhibits tumor angiogenesis, and induces tumor cell apoptosis in hepatocellular carcinoma model PLC/PRF/5. Cancer Res 66: 11851.

Llovet JM, Ricci S, Mazzaferro V, Hilgard P, Gane E, Blanc JF, de Oliveira AC, Santoro A, Raoul JL, Forner A, Schwartz M, Porta C, Zeuzem S, Bolondi L, Greten TF, Galle PR, Seitz JF, Borbath I, Haussinger D, Giannaris T, Shan M, Moscovici M, Voliotis D, Bruix J (2008) Sorafenib in advanced hepatocellular carcinoma. N Engl J Med 359: 378.

Lu KV, Chang JP, Parachoniak CA, Pandika MM, Aghi MK, Meyronet D, Isachenko N, Fouse SD, Phillips JJ, Cheresh DA, Park M, Bergers G (2012)
VEGF inhibits tumor cell invasion and mesenchymal transition through a MET/VEGFR2 complex. Cancer Cell 22: 21.

Martinho O, Longatto-Filho A, Lambros MB, Martins A, Pinheiro C, Silva A, Pardal F, Amorim J, Mackay A, Milanezi F, Tamber N, Fenwick K, Ashworth A, Reis-Filho JS, Lopes JM, Reis RM (2009) Expression, mutation and copy number analysis of platelet-derived growth factor receptor A (PDGFRA) and its ligand PDGFA in gliomas. Br J Cancer 101: 973.

Plastaras JP, Kim SH, Liu YY, Dicker DT, Dorsey JF, McDonough J, Cerniglia G, Rajendran RR, Gupta A, Rustgi AK, Diehl JA, Smith CD, Flaherty KT, El-Deiry WS (2007) Cell cycle dependent and schedule-dependent antitumor effects of sorafenib combined with radiation. Cancer Res 67: 9443.

Puputti M, Tynninen O, Sihto H, Blom T, Maenpaa H, Isola J, Paetau A, Joensuu H, Nupponen NN (2006) Amplification of KIT, PDGFRA, VEGFR2, and EGFR in gliomas. Mol Cancer Res 4: 927.

Reardon DA, Vredenburgh JJ, Desjardins A, Peters K, Gururangan S, Sampson JH, Marcello J, Herndon JEn, McLendon RE, Janney D, Friedman AH, Bigner DD, Friedman HS (2011) Effect of CYP3A-inducing anti-epileptics on sorafenib exposure: results of a phase II study of sorafenib plus daily temozolomide in adults with recurrent glioblastoma. J Neurooncol 101: 57.

Salmaggi A, Eoli M, Frigerio S, Silvani A, Gelati M, Corsini E, Broggi G, Boiardi A (2003) Intracavitary VEGF, bFGF, IL-8, IL-12 levels in primary and recurrent malignant glioma. J Neurooncol 62: 297.

Shih AH, Dai C, Hu X, Rosenblum MK, Koutcher JA, Holland EC (2004) Dose-dependent effects of platelet-derived growth factor-B on glial tumorigenesis. Cancer Res 64: 4783.

Stupp R, Mason WP, van den Bent MJ, Weller M, Fisher B, Taphoorn MJ, Belanger K, Brandes AA, Marosi C, Bogdahn U, Curschmann J, Janzer RC, Ludwin SK, Gorlia T, Allgeier A, Lacombe D, Cairncross JG, Eisenhauer E, Mirimanoff RO (2005) Radiotherapy plus concomitant and adjuvant temozolomide for glioblastoma. N Engl J Med 352: 987.

Taal W, Brandsma D, de Bruin HG, Bromberg JE, Swaak-Kragten AT, Smitt PA, van Es CA, van den Bent MJ (2008) Incidence of early pseudo-progression in a cohort of malignant glioma patients treated with chemoirradiation with temozolomide. Cancer 113: 405.

Vlassenbroeck I, Califice S, Diserens AC, Migliavacca E, Straub J, Di Stefano I, Moreau F, Hamou MF, Renard I, Delorenzi M, Flamion B, DiGuiseppi J, Bierau K, Hegi ME (2008) Validation of real-time methylation-specific PCR to determine O6-methylguanine-DNA methyltransferase gene promoter methylation in glioma. J Mol Diagn 10: 332.

Vredenburgh JJ, Desjardins A, Kirkpatrick JP, Reardon DA, Peters KB, Herndon JEn, Marcello J, Bailey L, Threatt S, Sampson J, Friedman A, Friedman HS (2012) Addition of bevacizumab to standard radiation therapy and daily temozolomide is associated with minimal toxicity in newly diagnosed glioblastoma multiforme. Int J Radiat Oncol Biol Phys 82: 58.

Wilhelm SM, Carter C, Tang L, Wilkie D, McNabola A, Rong H, Chen C, Zhang X, Vincent P, McHugh M, Cao Y, Shujath J, Gawlak S, Eveleigh D, Rowley B, Liu L, Adnane L, Lynch M, Auclair D, Taylor I, Gedrich R, Voznesensky A, Riedl B, Post LE, Bollag G, Trail PA (2004) BAY 43-9006 exhibits broad spectrum oral antitumor activity and targets the RAF/ MEK/ERK pathway and receptor tyrosine kinases involved in tumor progression and angiogenesis. Cancer Res 64: 7099.

This work is published under the standard license to publish agreement. After 12 months the work will become freely available and the license terms will switch to a Creative Commons AttributionNonCommercial-Share Alike 3.0 Unported License. 